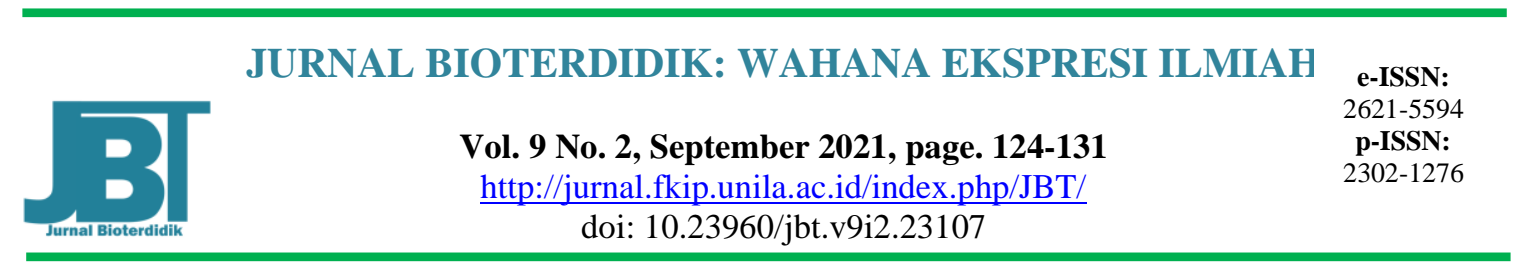

\title{
Analisis Kemampuan Berpikir Kritis dalam Pembelajaran Biologi Siswa Kelas XI SMAN 1 Tanah Putih Rokan Hilir
}

\author{
Sepita Ferazona*, Suryanti, Sri Amnah, Siti Robiah,Tengku Idris \\ Pendidikan Biologi, Fakultas Keguruan dan Ilmu Kependidikan,Universitas Islam Riau, Jl. Kaharudin \\ Nasution No. 113, Pekanbaru, Riau, Indonesia \\ *e-mail: sepitabio@edu.uir.ac.id, No Hp.085222272131
}

Received: September 15, 2021

Accepted: September 25, 2021

Online Published: September 30,2021

\begin{abstract}
Analysis of Critical Thinking Ability in Biology Learning for Class XI Students of SMAN 1 Tanah Putih Rokan Hilir. This study aims to see the Critical Thinking Ability in the Materials of the Respiratory System of Class XI SMAN 1 Tanah Putih Subdistricts. The sample of this study consisted of one class, the determination of the sample by using purposive sampling technique. This type of research is survey research with a qualitative descriptive approach. The data obtained is the students' critical thinking ability. The percentage of gain in SMAN 1 Tanah in Focus indicator gets a percentage of $66 \%$ in the high category, the argument indicator gets a percentage of 13.20 with a very low category, the conclusion indicator gets a percentage of $56.56 \%$ in the medium category, the situation indicator gets a percentage of $47.1 \%$ with the medium category, the follow-up indicator obtained a percentage of $3.85 \%$ with a very low category
\end{abstract}

Keywords: critical thinking, learning, respiratory system

\begin{abstract}
Abstrak: Analisis Kemampuan Berpikir Kritis dalam Pembelajaran Biologi Siswa Kelas XI SMAN 1 Tanah Putih Rokan Hilir. Penelitian ini bertujuan untuk melihat Kemampuan Berpikir Kritis pada materi Sistem Pernapasan Siswa Kelas XI SMAN 1 Kecamatan Tanah Putih. Sampel penelitian ini terdiri dari satu kelas, penentuan sampel dengan dengan menggunakan teknik sampling purposive. Jenis penelitian ini adalah penelitian survei dengan pendekatan deskriptif kualitatif. Data yang diperoleh ialah kemampuan berpikir kritis siswa. Persentase perolehan di SMAN 1 tanah pada Indikator fokus memperoleh persentasi $66 \%$ dengan katagori tinggi, indikator argumen memperoleh persentasi 13,20 dengan katagori sanagat rendah, indikator kesimpulan memperoleh persentasi 56,56\% dengan katagori sedang, indikator situasi memperoleh persentasi 47,1\% dengan katagori sedang, indikator tindak lanjut memperoleh persentasi 3,85\% dengan katagori sangat rendah.
\end{abstract}

Kata kunci: berpikir kritis, pembelajaran, sistem pernapasan 


\section{PENDAHULUAN}

Pemerintah Indonesia banyak melakukan perbaikan sistem pendidikan untuk meningkatkan kualitas pendidikan. Salah satu perbaikan sistem pendidikan di Indonesia adalah perbaikan kurikulum. Kurikulum yang sedang diterapkan saat ini adalah Kurikulum 2013. Kurikulum 2013 merupakan kurikulum yang mengarahkan pada pencapaian kompetensi yang dirumuskan dari standar kompetensi lulusan. Standar kompetensi lulusan itu ada sikap, perilaku, pengetahuan, serta keterampilan. Keterampilan yang dibutuhkan dalam kurikulum 2013 adalah keterampilan berpikir kritis (Anggriasari, 2018: 184). Oleh karena itu, melalui kemampuan berpikir kritis yang dimiliki siswa, mereka diharapkan bisa menganalisis sesuatu yang berguna atau tidak berguna bagi dirinya sendiri, keluarga, maupun masyarakat dan bangsanya.

Berpikir kritis harusnya sudah dilatih sejak pada tingkat SMP, sehingga siswa dapat melatih pola pikir dan mengatih mesalah-masalah yang ada disekitar dan pada diri sendiri, materi system saraf dan system imun adalah pengetahuan yang harus dipahami siswa, dengan pola berpikir kritis yang di biasakan dapat membantu siswa dalam memahami diri sendiri dan lingkungannya. Dengan kemamuan berpikir kritis yang dimiliki siswa diharapkan dapat mengembangkan ilmu pengetahuan dan teknologi yang berkembang saat ini.

Pembelajaran Biologi merupakan salah satu cabang dari IPA. Biologi merupakan ilmu pengetahuan alam yang diajarkan pada setiap jenjang pendidikan. Biologi merupakan ilmu dalam proses menemukan pengetahuan melalui pengamatan secara langsung, pengalaman dan pembelajaran. Biologi melatih siswa untuk lebih menghargai kekuatan tuhan dan penciptaan. Terkait dengan proses pembelajaran Biologi, guru seringkali menemukan siswa kurang memahami konsep-konsep Biologi secara mendalam padahal pemahaman konsepkonsep Biologi sangat diperlukan dalam pengintegrasian alam dan teknologi. Hal ini mengkin saja disebabkan di dalam pembelajaran kurangnya keterlibatan siswa dan kurangnya penekanan guru terhadap keterkaitan antara konsep-konsep Biologi dan lingkungan riil.

Melatih berpikir kritis siswa merupakan salah satu tujuan dari kurikulum yang termuat dalam kerangka dasar dan struktur kurikulum SMA/MA dan tuntutan bagi guru yang tercantum pada kompetensi lulusan pendidikan dasar dan menengah. Peneliti melakukan penelitian berpikir kritis berdasarkan indikator yang dibuat oleh Ennis, sehingga bisa menghasilkan kriteria berpikir kritis yang berbeda dengan penelitian yang sebelumnya. Menurut Ennis, (1981: 4) indikator berpikir kritis itu mencakup dari fokus, argument, kejelasan, situasi, kesimpulan, dan tinjauan lanjut. Dengan demikian dalam proses pembelajaran, guru di kelas perlu memberikan soal-soal latihan sesuai indikator berpikir kritis, atau pada soal-soal ulangan harian, UTS atau Ujian Semester walaupun hanya beberapa butir saja. 
Berdasarkan uraian di atas, yang menunjukkan bahwa tingkat keterampilan berpikir kritis di SMA N 1 Pekanbaru masih rendah. Maka penulis tertarik melakukan penelitian ini untuk memperoleh gambaran Profil Keterampilan Berpikir Kritis dalam Pembelajaran Biologi Siswa Kelas XI SMAN 2 Pekanbaru Pada Materi Sistem Eksresi Tahun Ajaran $2019 / 2020$.

\section{METODE}

Penelitian ini dilaksanakan di SMAN 1 Tanah Putih Kabupaten Rokan Hilir. Penelitian ini dilakukan pada bulan Mei hingga Agustus 2021. Sampel penelitian 59 siswa. Jenis penelitian ini adalah penelitian survei dengan pendekatan deskriptif kualitatif. Data yang diperoleh dianalisis dengan menggunakan teknik analisis data kuantitatif. Penilaian kemampuan berpikir kritis dilakukan sesuai dengan enam indikator berpikir kritis yaitu: 1) Fokus (fokus), 2) Argumen (Reason), 3) Kesimpulan (inference), 4) Situasi (Situation), 5) Kejelasan (Clarity), 6) Tinjauan Lanjut (Overview). Adapun kisi-kisi soal berpikir kritis pada Tabel 1.

Tabel 1. kisi-kisi soal berpikir kritis

\begin{tabular}{|l|c|}
\hline \multicolumn{1}{|c|}{ Indikator berpikir kritis } & Sistem Pernapasan \\
\hline Fokus (Focus) & $10,13,14$ \\
\hline Argumen (Reason) & $9,15,16$ \\
\hline Kesimpulan (inference) & $3,4,7,8$ \\
\hline Situasi (Situation) & $2,11,12$ \\
\hline Kejelasan (Clarity) & 1,5 \\
\hline Tinjauan Lanjut (Overview) & 6,17 \\
\hline
\end{tabular}

Menentukan tingkat keterampilan siswa berdasarkan kriteria keterampilan berpikir kritis 17 pertanyaan pada setiap materi dan banyaknya kelas dapat ditentukan dengan kriteria skor berdasarkan Tabel 2.

Tabel 2. Kategori persentase kemampuan berpikir kritis

\begin{tabular}{|c|c|}
\hline Interpretasi & Kategori \\
\hline $80<\mathrm{PK} \leq 100$ & Sangat Tinggi \\
\hline $60<\mathrm{PK} \leq 80$ & Tinggi \\
\hline $40<\mathrm{PK} \leq 60$ & Sedang \\
\hline $20<\mathrm{PK} \leq 40$ & Rendah \\
\hline $0<\mathrm{PK} \leq 20$ & Sangat Rendah \\
\hline
\end{tabular}

Sumber: Arini (2018: 7) 


\section{HASIL DAN PEMBAHASAN}

Data kemampuan berpikir kritis mahasiswa diperoleh dari tes uraian, yang dijabarkan pada Tabel 3. Kemampuan Berpikir Kritis berdasarkan indikator fokus memperoleh persentasi $66 \%$ dengan katagori tinggi, indikator argumen memperoleh persentasi 13,20 dengan katagori sanagat rendah, indikator kesimpulan memperoleh persentasi 56,56\% dengan katagori Sedang, indikator situasi memperoleh persentasi 47,1\% dengan katagori sedang, indikator tindak lanjut memperoleh persentasi 3,85\% dengan katagori sangat rendah.

Tabel 3. Presentase soal indikator berpikir kritis kategori fokus sistem pernapasan

\begin{tabular}{|l|l|l|l|l|l|l|}
\hline \multicolumn{7}{|c|}{ Indikator Berpikir Kritis } \\
\hline & Fokus & Argumen & Kesimpulan & Situasi & Kejelasan & $\begin{array}{l}\text { Tinjauan } \\
\text { Lanjut }\end{array}$ \\
\hline Rata-rata & $66 \%$ & $13,20 \%$ & $56,56 \%$ & $47.13 \%$ & $37.71 \%$ & $3.85 \%$ \\
\hline Kategori & Tinggi & $\begin{array}{l}\text { Sangat } \\
\text { Rendah }\end{array}$ & Sedang & Sedang & Rendah & $\begin{array}{l}\text { Sangat } \\
\text { Rendah }\end{array}$ \\
\hline
\end{tabular}

Perbandingan persentase dari masing-masing soal dengan indikator argument pada meteri Sistem pernapasan dapat dilihat pada Gambar 1. Soal berpikir kritis yang sudah dikerjakan menunjukkan katagori yang sedang, rendah dan sangat rendah. Dengan jumlah 17 soal Pilihan Ganda. Menunjukkan kemampuan berpikir kritis siswa kurang baik. Menurut Fisher (2008) bahwa berpikir kritis merupakan berpikir yang tidak langsung mengarah ke kesimpulan atau menerima beberapa bukti, tuntutan atau keputusan begitu saja tanpa sungguh-sungguh memikirkannya dan critical thinking (berpikir kritis) dengan jelas menuntut interpretasi dan evaluasi terhadap observasi, komunikasi dan sumbersumber informasi lainnya.

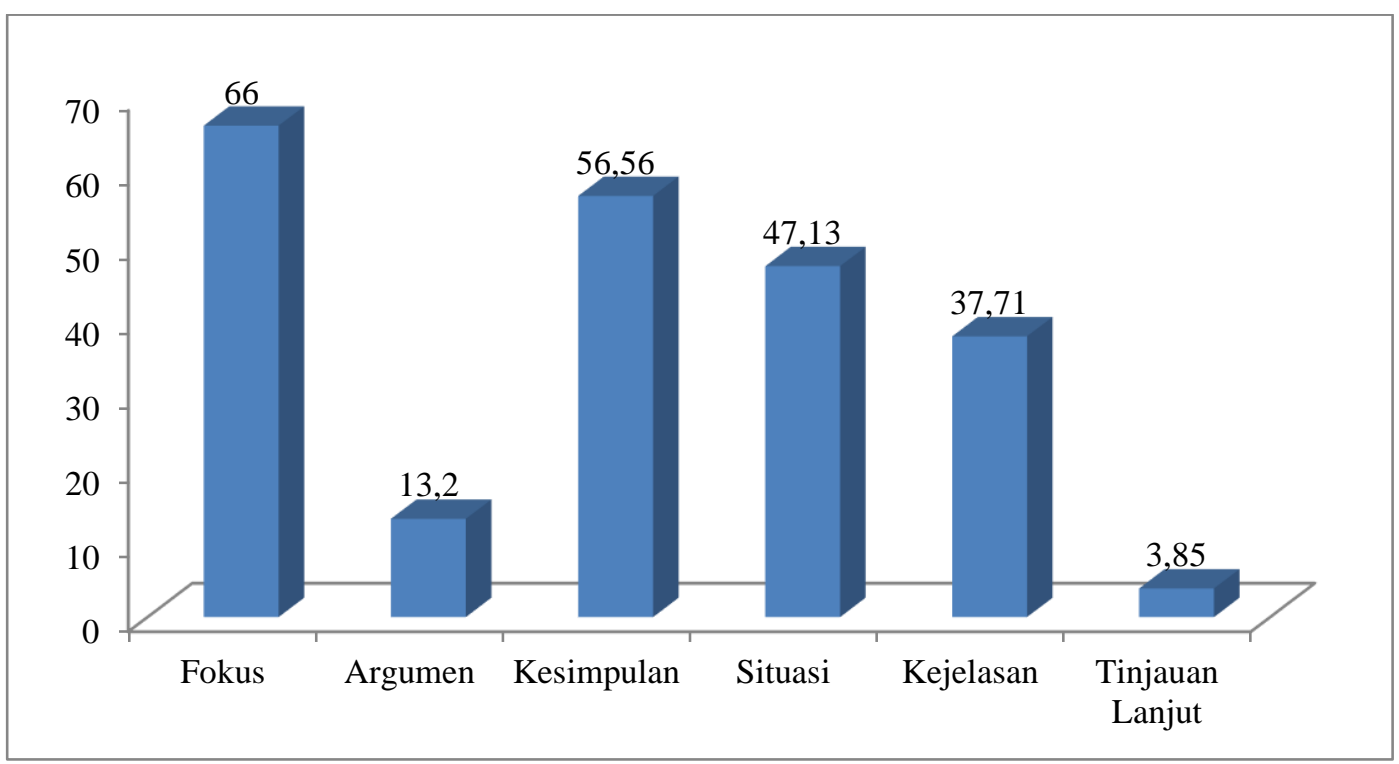

Gambar 1. Perbandingan persentase dari masing-masing soal dengan indikator argument pada meteri Sistem pernapasan 
Keterampilan berpikir kritis peserta didik memiliki nilai persentase sebesar 50,95\% dengan kategori sedang (Anggiasari, 2018). Tingkat pengguasaan Keterampilan berpikir kritis peserta didik di Kecamatan Ilir Timur II memiliki nilai persentase sebesar 50,43\% dikategorikan sedang dan indikator tertinggi yaitu dengan indikator pengaturan diri dengan rata-rata 63,33\% dengan kategori tinggi dan indikator terendah menjelaskan dengan rata-rata 46,83\% dengan kategori sedang. Berdasarkan hasil wawancara dengan siswa diambil kesimpulan bahwa pada indikator "tinjauan lanjut" ada sebagian siswa menjawab itu termasuk kategori sedang ada juga sebagian mengatakan indikator tersebut mudah, karena pada indicator tersebut ada yang mudah dipahami siswa da nada yang sulit dipahami siswa. Hal ini sejalan dengan penelitian oleh Anggiasari (2018) bahwa keterampilan berpikir kritis peserta didik di Kecamatan Kalidoni memiliki nilai persentase sebesar 50,95\% dengan kategori sedang dan indikator tertinggi yaitu indikator pengaturan diri dengan rata-rata $64,29 \%$ dengan kategori tinggi dan indikator terendah mengevaluasi dengan rata-rata 41,27\% dengan kategori rendah.

Berpikir kritis merupakan proses dimana segala pengetahuan dan keterampilan dikerahkan dalam memecahkan permasalahan yang muncul, mengambil keputusan, menganalisis semua asumsi yang muncul dan melakukan investigasi atau penelitian berdasarkan data dan informasi yang telah didapat sehingga menghasilkan informasi atau simpulan yang diinginkan (Ariyana, 2018). Berpikir kritis dengan jelas menuntut interpretasi dan evaluasi terhadap observasi, komunikasi, dan sumber-sumber informasi lainnya. Soal evaluasi selalu didahului kasus yang ditelaah oleh siswa dengan teropong hukum, prinsip, dan kemudian melakukan penilaian baik atau tidak berdasarkan benar dan salah (Arikunto, 2012). Kemampuan evaluasi adalah menciptakan kondisinya sedemikian rupa sehingga siswa mampu mengembangkan kriteria, standar atau ukuran unutuk mengevaluasi sesuatu (Daryanto, 2012). Level mengevaluasi merupakan kemampuan dalam mengambil keputusan berdasarkan kriteria-kriteria tertentu (Nugroho, 2018).

\section{SIMPULAN}

Hasil Penelitian di SMAN 1 Tanah Putih menunjukkan dari 17 soal berpikir kritis yang diuji memperoleh presentasi yang berbeda. Indikator fokus memperoleh persentasi 66\% dengan katagori tinggi, indikator argumen memperoleh persentasi 13,20 dengan katagori sanagat rendah, indikator kesimpulan memperoleh persentasi 56,56\% dengan katagori Sedang, indikator situasi memperoleh persentasi 47,1\% dengan katagori sedang, indikator tindak lanjut memperoleh persentasi 3,85\% dengan katagori sangat rendah.

\section{DAFTAR RUJUKAN}

Afrianto, F. (2016). Penerapan Model Pembelajaran Problem Based Learning pada Materi Hukum Newton untuk Meningkatkan Kemampuan Berpikir Kritis Siswa Kelas X SMA Negeri PLUS Provinsi Riau. Skripsi. Universitas Riau. Pekanbaru. 
Amri, S., \& Ahmadi I, K. (2010). Proses Pembelajaran Inovatif dan Kreatif di dalam Kelas. Jakarta: PT Prestasi Pustakaraya.

Arikunto, S. (2012). Dasar-Dasar Evaluasi Pendidikan.Jakarta: Bumi Aksara.

Ariyana, Y.dkk. (2018). Buku Pegangan Pembelajaran Berorientasi Pada Keterampilan Berpikir Tingkat Tinggi. Jakarta: Tim Desain Grafis.

Anggiasari, T., Saleh, H \& Binnar, AAH. (2018). Analisis Ketrampilan Berpikir Siswa SMA Kecamatan Kalidoni dan Ilir Timur II. Bioma. Universitas Muhammadiyah Palembang. Volume 7.Nomor 2. Tahun 2018.Hlm. 184-195 (Diunduh 24 September 2019, Pukul 21: 51).

Arini, W., \& Fikri, J. (2018). Analisis Kemampuan Berpikir Kritis Pada Mata Pelajaran Fisika Untuk Pokok Bahasan Vektor Siswa Kelas X Sma Negeri 4 Lubuklinggau, Sumatera Selatan. Berkala Fisika Indonesia. STKIP PGRI Lubuk linggau. Volume 10. Nomor 1. Hlm. 1-11 (Diunduh 9 Juni 2020, Pukul 10.50).

Ayuningrum, D., \& Susilowati. (2015). Pengaruh Model Problem Based Learning Terhadap Keterampilan Berpikir Kritis Siswa Sma Pada Materi Protista. Jurnal Pendidikan IPA Unnes. (Nomor 2 Tahun 2015). Hlm. 1-2.

Daniati N, dkk. (2018). Analisis Tingkat Kemampuan Berpikir Kritis Peserta Didik kelas VII SMP 2 Padang tentang materi Pencemaran Lingkungan. Jurnal Biologi. UNP. (Diunduh 28 Juni 2020).

Daryanto. (2012). Evaluasi Pendidikan. Jakarta: Rineka Cipta.

Fakhriyah, F. (2014). Penerapan Problem Based Learning Dalam Upaya Mengembangkan Kemampuan Berpikir Kritis Mahasiswa. Jurnal Pendidikan IPA Unnes. (Nomor 1 Tahun 2014). Hlm. 1-2.

Fisher, A. (2008). Berpikir Kritis: Sebuah Pengantar. (Alih Bahasa: Benyamin Hadinata). Jakarta: Erlangga.

Hamalik, U. (2003). Kurikulum dan Pembelajaran. Jakarta: Bumi Aksara.

Hamdani, M.A. (2011). Strategi Belajar Mengajar. Bandung: CV Pustaka Setia. 
Hanafiah, N. \& Cucu, S. (2010). Konsep Strategi Pembelajaran. Bandung: Refika Aditama.

Inch, E. S. et al (2006). Critical Thingking and Communication The Use of Reason in Argument. Edisi 5. Wasington.

King, et al. (2000). Higher Order Thinking Skills. Assessment Evaluation Educational Services Program. [Online]. Tersedia: http://www.cala.fsu.edu. [20 Februari 2017].

Nugroho, AR. (2018). Higher Order Thinking Skills (HOTS). Jakarta. Gramedia Widiasiarana Indonesia.

Rusman. (2011). Model-Model Pembelajaran Mengembangkan Profesionalisme Guru. Jakarta: PT. Rajagrafindo Persada.

Sanjaya, W. (2013). Penelitian Pendidikan: Jenis, Metode, dan Prosedur. Jakarta: Kencana.

Sari, N.K. (2014). Sikap Ilmiah dan Metode Imiah. Online. Tersedia di: http://nuriithaa.blogspot.co.id/2014/03/sikap-ilmiah-dan-metode-ilmiah.html, (Diakses 13 Juli 2016)

Sudjana, N. (2005). Metoda Statistika. Bandung: Tarsito.

Sugiyono. (2010). Metode Penelitian Pendidikan Kuantitatif, Kualitatif, dan R\&D. Bandung: Alfabeta.

Suryabrata, S. (2010). Psikologi Pendidikan. Jakarta: PT Rajagrafindo Persada.

Suryobroto, B. (2009). Proses Belajar Mengajar di Sekolah. Jakarta: PT Rineka Cipta.

Stiggins, R. J. (1994). Student-Centered Classroom Assessment. New York: Merrill, an imprint of Macmillan College Publhing Company.

Sanjaya, W. (2008). Perencanaan dan Desain Pembelajaran. Jakarta: Kencana. 
Trianto. (2010). Model-model Pembelajaran Terpadu. Jakarta: Bumi Aksara.

Zaini, H. (2008). Strategi Pembelajaran Aktif. Yogyakarta: Insan Mandiri.

Zaini, M., Kaspul \& Amalia R. (2018). Hasil Belajar dan Keterampilan Berpikir Kritis Siswa SMA pada Pembelajaran Biologi Menggunakan Model Inkuiri. Jurnal Pendidikan Biologi. Universitas Lambung Mangkurat Banjarmasin. Volume 11. Nomor 1. ISSN: 1693-265X. Hlm.17-22. (Diunduh 6 Oktober 2019, Pukul 17:14). 